\title{
Human-Animal Teams as an Analog for Future Human-Robot Teams: Influencing Design and Fostering Trust
}

\author{
Elizabeth Phillips \\ Institute for Simulation \& Training, University of Central \\ Florida
}

\author{
Kristin E. Schaefer \\ U.S. Army Research Laboratory \\ Deborah R. Billings \\ Agilis Consulting Group, LLC
}

Florian Jentsch

Institute for Simulation \& Training, University of Central

Florida

and

\section{Peter A. Hancock \\ Institute for Simulation \& Training, University of Central \\ Florida}

Our work posits that existing human-animal teams can serve as an analog for developing effective human-robot teams. Existing knowledge of human-animal partnerships can be readily applied to the HRI domain to foster accurate mental models and appropriately calibrated trust in future human-robot teams. Human-animal relationships are examined in terms of the benefiting roles animals can play in enabling effective teaming, as well as the level of team interdependency and team communication, with the goal of developing applications in future human-robot teams.

Keywords: human-robot interaction, human-animal interaction, mental models, trust

\section{Introduction}

Recent years have seen a massive growth in global investments of robotic technologies across a variety of sectors that now include a number of nontraditional robotic domains. The integration of robotic technologies has led to the reimagining of robots as assets that more closely resemble interactive companions. This has led to the need for a transition of the robot's role from a tool to

Authors retain copyright and grant the Journal of Human-Robot Interaction right of first publication with the work simultaneously licensed under a Creative Commons Attribution License that allows others to share the work with an acknowledgement of the work's authorship and initial publication in this journal. 
Phillips et al., Human-Animal Teams as an Analog

an interactive team member. This transition to future design is most commonly envisioned for areas that require extensive social interaction with the general populous or in high-risk environments that require increasingly interdependent forms of teaming between humans and robots. For example, the future vision of military robots is one in which robots will possess capabilities that allow them to serve as team members alongside soldiers, working to achieve common goals and complete team tasks (e.g., small unit military fire teams; Army Research Laboratory, 2011). As such, robots will be expected to move dynamically within their team, maintain mission and situation awareness, understand salient features of their environment, and proactively share information with their human companions.

However, the development of human teammate-like competence (e.g., cognitive architectures, theory of mind, ability to react appropriately in dynamic team environments) is severely limited by the progress of the current state of the art in robotic technologies. These contemporary and presumably temporary constructs imply that, in the near term, robots will not fully replicate their human counterparts in functionality or intelligence capacities. Yet, to meet the needs for near-term development, robots will need to possess a subset of skills that can be leveraged to perform work, not unlike the ways that working animals are utilized (see Groom \& Nass, 2007; Hancock, 1997; Helton, 2009). Therefore, human-animal teams serve as a convenient analog for imagining nearterm design capabilities of robots, because these teams are capable of completing a wide variety of work by leveraging the unique capacities of each team member (both human and animal). Interaction mechanisms used by human-animal teams allow us to forecast what soldier-robot teaming, for example, could resemble in the near future.

The purpose of our paper then is to provide insight into the near-future stages of human-robot teaming through an examination of the different human-animal team types. Our goal is to extrapolate for future trust and performance in these up-and-coming human-robot teams. To begin, we explore why the analog of a human-animal team can be a useful mechanism for supporting human mental models of robots. Then, we review the functional benefits that human-animal teams provide, the capabilities that support teamwork, and how trust is engendered, developed, and sustained in these types of teams. Two key features that support human-animal teaming include communication and interdependent interaction. To conclude, we discuss how the human-animal teamwork metaphor can be leveraged to inform future human-robot teams, with an especial eye toward critical military contexts.

\section{Mental Models of Robots: The Human-Animal Team Analogy}

Although the capabilities for modeling complex human-like teammate relationships in humanrobot teams may not exist (yet), we may draw upon other teammate-like relationships for design guidance (e.g., including interaction patterns, forms of communication, and features that engender trust). For instance, human-animal teams function with an implied interaction hierarchy, in which humans generally maintain authority over animals (Morrow \& Fiore, 2012). Similar human-robot interaction designs may be beneficial for contexts in which devolving inter-team authority is a possibility and in which designing for the human-robot team to fail gracefully represents an ongoing challenge (e.g., soldier-robot teams working in battlefield environments). The humananimal team analogy provides some level of insight that can help transition some of the 'unknownunknowns' to 'known-unknowns' during the near-term transition of a robotic system away from teleoperations or control-by-wire. This knowledge can be leveraged to determine possible design characteristics and training that influence a person's expectations toward future interaction. These expectations, along with knowledge estimations and attitudes, play a significant role in mental model formation and trust in relationships in general.

Mental models refer to structured, organized knowledge possessed by humans that describe, explain, and predict a system's purpose, form, function, or state (Rouse \& Morris, 1986). These models impact how people interact with the world around them and are continuously being 
modified and updated as new information is acquired. This is especially the case concerning systems with which people are unfamiliar (Norman, 1983). Prior research has suggested that mental models of robots are easily influenced by superficial features, including robotic form (i.e., the presence of anthropomorphic or biologically inspired limbs, the presence of extraneous hardware; Kiesler \& Goetz, 2002; Sims et al., 2005), perceived country of origin (Lee, Kiesler, Lau, \& Chiu, 2005), and the way robots communicate (Torrey, Fussell, \& Kiesler, 2013). This relationship between physical forms and mental models has been shown to influence initial perceptions of robot trustworthiness (Schaefer, Sanders, Yordon, Billings, \& Hancock, 2012b). Yet, people often hold ill-formed or incomplete mental models of robots, which do not necessarily align with the true behavior, capabilities, or limitations of current robotic systems (Hancock, Billings, \& Schaefer, 2011a). This misalignment of an individual's mental model and the actual system is, in part, due to the general populous' access to depictions of robots in popular culture and fictional media, which are infused with portrayals of robots that do not represent actual capabilities of contemporary and real-world robots (see Schaefer, Adams, Cook, Bardwell-Owens, $\&$ Hancock, 2015). Problematically, therefore, human mental models of robots often more closely resemble popular depictions of robots rather than actual real-world robots (Ososky, Phillips, Schuster, \& Jentsch, 2013). This is important, because prior research on human interaction with automated systems has shown that when expectations are unmatched by reality, humans are likely to distrust or discontinue using the automated system (Parasuraman, \& Riley, 1997). As such, trust and mental models will be central to successful human-robot interaction with near-future robots. Trust will dictate whether or not humans choose to rely on robots in human-robot team tasks (Phillips, Ososky, \& Jentsch, 2014), and mental models will provide the foundation for that trust, by supporting human understanding of the capabilities and limitations of their robotic teammates (Ososky, Schuster, Phillips, \& Jentsch, 2013). Human-animal team analogs can be one means through which to foster veridical mental models of robots that provide a more accurate representation of their near-future capabilities. Additionally, human-animal team analogs of interaction, as opposed to adult-child, or human-human analogs, also imply that full human emulation in robots is not necessary for successful human-robot team performance.

Research has shown that analogies can be used to refine mental models and allow individuals to leverage perceived similarities between concepts for subsequent generalization (Genter \& Holyoak, 1997). For instance, the desktop and file drawer metaphors for computer operating systems were first introduced at the genesis of home computing. Human-animal team analogs can be one means through which to foster veridical mental models of robots that provide a more accurate representation of their near-future capabilities. One of the most common analogies is through the direct emulation of animal characteristics and behaviors in technology. The support for this sentiment is founded in the work on 'shaping.' For example, Helton (2010) found that the shape or physical form of an animal influences how people form perceived attributions related to that animal's intelligence. Further, Finkbeiner, Russell, and Helton (2014) found that people, even those with minimal experience interacting with dogs, were able to form immediate impressions regarding the dog's personality or functional capabilities based on shape information alone. This relationship between physical form to perceived intelligence and expected capabilities has been mirrored in human-robot interaction (HRI) and was shown to influence initial perceptions of trustworthiness (Schaefer et al., 2012b). Several existing robots are designed to look or behave like animals (e.g., zoomorphic, such as $A I B O$ ), primarily to evoke certain responses from humans or for task or physical environment functionality (Coeckelbergh, 2011). Others employ animalinspired architecture to navigate in certain terrains and add to functionality. For example, BigDog is a legged robot designed to function essentially as a pack mule and traverse terrain not accessible by wheeled or tracked vehicles (Raibert, Blankespoor, Nelson, \& Playter, 2008). Even the behaviors of bees, birds, and ants supply the underlying computer architecture for modern robotics and computer programming related to path finding, load balancing, communication, and navigation in unknown terrains (e.g., Boyd's flocking model, ant colony optimization; Balch \& 
Phillips et al., Human-Animal Teams as an Analog

Arkin, 1995; Reynolds, 1987; Vaughan, Støy, Sukhatme, \& Matarić, 2002). Robotic designs inspired by nature (biomimetic designs) have brought about tremendous changes and improvements, especially concerning the dexterous and unique mobility of robots (Hancock, 2015). Other relevant examples include octopi-inspired swimming robots (Ackerman, 2014), swarm behaviors in nano-UAVs (Werner, 2013), and cheetah-inspired, fast, four-legged locomotion (Newman, 2014).

While animal-inspired designs have aided in improved robotic movement and manipulation, we maintain that design inspired by human-animal teaming can provide similar gains in robotic development, especially as it concerns improved human-robot interaction and teaming. As most people have far more experience interacting with animals than with robots, they are generally more able to recognize limitations in an animal's ability to complete a task (Phillips, Ososky, Swigert, \& Jentsch, 2012). Along these lines, it is advantageous for design and training programs of near-future robots to make use of established working relationships with animals that humans have cultivated over centuries of interaction. Similarly, it may also be advantageous to make use of established training paradigms, as similar techniques have been successfully used to train synthetic agents (Blumberg et al., 2002).

In consequence, robotic designs inspired by human-animal relationships can lead to faster acceptance while fostering more effective interactions between humans and robots, as humans tap into well-established mental models, promote better understanding of near-future robots, and thus appropriately calibrate trust in near-future robotic teammates.

\section{Human-Animal Teaming: A Vision for Human-Robot Teaming}

While robotic mirrors of human-animal teams exist, many of these do not (yet) offer a complete solution or suitable stand-in for animals in all situations. However, our understanding of varying types of human-robot interactions can be improved by drawing comparisons with human-animal partnerships (Coeckelbergh, 2011). Human-animal teams may specifically help address or identify current technology limitations specific to cognition, perception, action, and human-robot interaction. Animals have been chosen and actively domesticated to fulfill these different roles based on their natural abilities, instincts, characteristics, and functional capabilities (e.g., a horse for riding, a carrier pigeon for long-distance communication, or a dog for guidance of the blind). These relationships represent a unique form of partnership that often directly benefits humans physically, emotionally, and cognitively (Wilson, 1994). Here, we expand on different types of human-animal teams that have been used to successfully benefit people. We provide this review for the purpose of understanding the different types of human-animal teams that currently exist and provide a reference for future roboticists to consider during the development stage of the robot lifecycle. Bi-directional communication and interdependency are research areas that still need improvement and could benefit from a more in-depth look at human-animal teams (this topic will be discussed at length later in the paper).

\section{Human-Animal Teams: Physical Benefits}

Robot action specific to mobility and manipulation has made major advances within controlled and simulated settings (e.g., lifting massive objects, precision, and repeatability). However, outside these controlled settings, they currently require teleoperation due to the challenging operational environment characteristics (e.g., people, dynamic environments, objects, and sensory variations; Kemp, Edsinger, \& Torres-Jara, 2007). Additionally, robots struggle with many perceptual tasks, including perception-based autonomous navigation, especially in cluttered and complex terrain (Jackel et al., 2007; Nguyen-Huu, Titus, Tilbury, \& Ulsoy, 2009). By looking at human-animal teams used to provide physical benefits to people, we are able to start identifying team structure elements that might help advance mobility, manipulation, and perception limitations of current human-robot teams. 


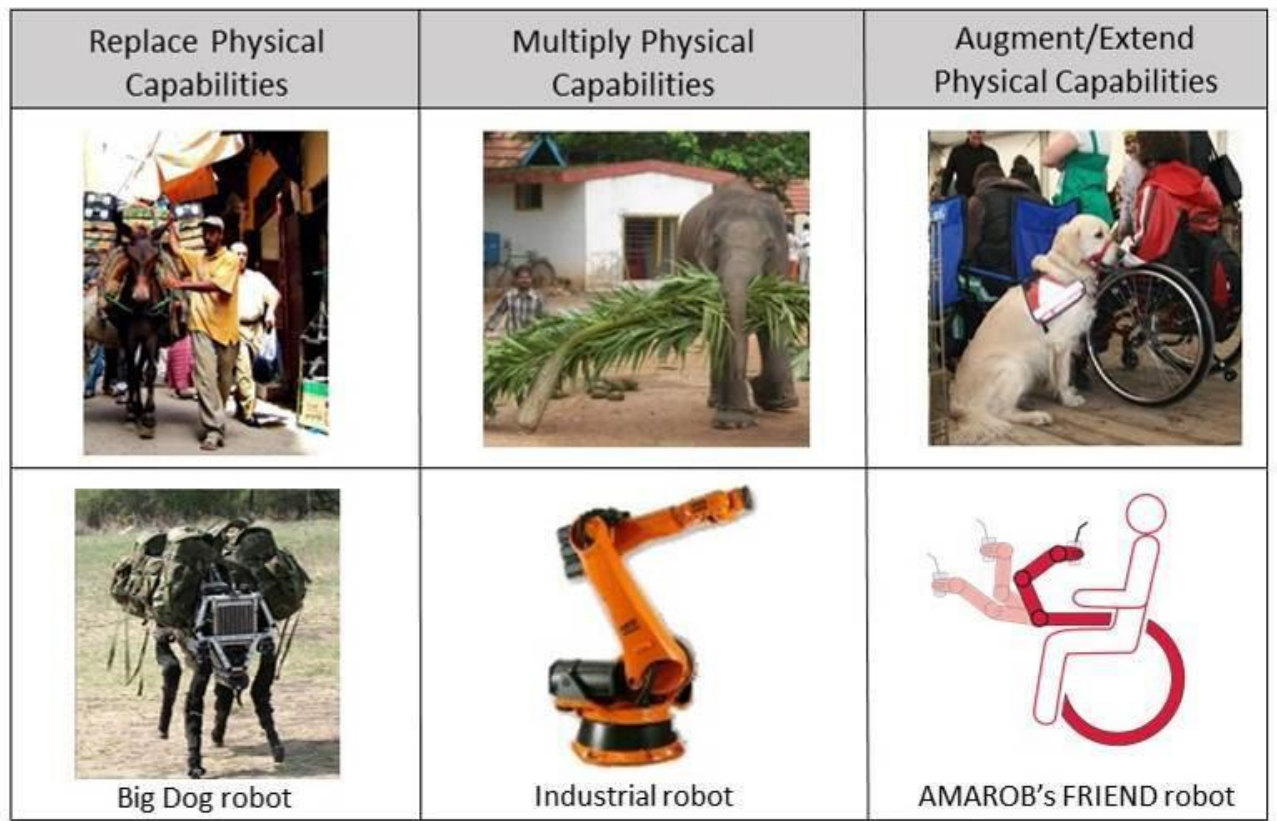

Figure 1: Physical benefits of human-animal relationships paralleled in robotic development

Here, we look at human-animal teams that have been used to provide physical benefits requiring advanced action and perception in order replace, multiply, or augment a person's physical needs. Fig. 1 is not all inclusive, but we present it here to provide some examples of human-animal teams that can be leveraged for current and future robotic systems.

Historically, the most direct benefit of human-animal teaming has been to replace physical capabilities of the person with the animal's innate ability to exceed current human ability. A prime example is reflected in improved locomotion capabilities. This is most commonly seen in animals that serve as mount or pack transporters (e.g., horse, elephant, camel-rider relationship, or pack mules). Here, the animals provide more efficient locomotion for transportation of other people or cargo (Klinkenborg, 1993; Mills, 2002; Nesbitt \& Nesbitt, 2004; The Robinson Ranch, 2003). This type of human-animal teaming is one that has now been quite extensively explored within the robotics community. For example, Boston Dynamics (now owned by Google) designed and built a military robot, Big Dog, to carry cargo in order to reduce soldier load (Boston Dynamics, 2013). The design of Big Dog mirrors that of a large dog or small mule in order to successfully locomote in rough or uncertain terrain. More recent efforts have also been in the transportation area with the design and development of a robotic passenger vehicle (see Gannes, 2014). In this arena, improving human movement capabilities has primarily been accomplished through improvements in robotic locomotion, specifically improved quadrupedal movement in the case of the Big Dog, and automated driving in the case of Google's self-driving vehicle.

Another form of human-animal teaming is one in which the animal multiplies human physical capabilities. Here, animals have been leveraged to assist people with tasks that exceed human capabilities, such as lifting or pulling heavy objects or tasks requiring extended stamina. For example, an ox is used to assist farmers with plowing fields and pulling heavy equipment ("Oxen Team Practice," 2010). The robotics field has traditionally leveraged this type of teaming in manufacturing and/or industrial domains. This technology built on George Devol's work in the 1950 's on programmable transfer machines and led to the creation of the robotic arm (e.g., 
Stanford arm, designed by Victor Scheinman in 1969 at Stanford University). As stated previously, the development of robotics for this type of function is rather advanced within controlled environments; however, human-robot teaming is moving into unstructured environments. For example, more recent applications have extended to areas like search and rescue (SAR), in which robotic arms are used to lift heavy objects, as well as to medical domains in which robotic arms are used to lift patients out of beds or into assistive chairs (e.g., RIBA, robot nurse). Human-animal teams have been successful in semi-structured and unstructured environments, and this perspective can thus be leveraged. Human-animal teaming can also provide direct assistance to humans with specific physical limitations or disabilities. These animal teammates are often found in the physical therapy and service domains. Service animals can augment and extend natural human functions. Such animals can help to enhance an individual's independence and execution of daily activities that they would not be able to perform safely on their own (Watts \& Everly, 2009; Zapf \& Rough, 2002). For example, according to the Americans With Disabilities Act of 1990 (C.F.R.§ 36.104, 2002), a service animal may be used for "guiding individuals with impaired vision, alerting individuals with impaired hearing to intruders or sounds, providing minimal protection or rescue work, pulling a wheelchair or fetching dropped items." Such animals also reduce stress by allowing individuals to retain a greater degree of selfdetermination and dynamic adaptation to immediate and prospective environments. Service animals, therefore, provide a means for individuals to live more independently. This is an area in which robots are beginning to play their surrogate role, especially for therapies involving mobility related issues. Examples include the care-providing robot FRIEND (Functional Robot arm with user-frIENdly interface for Disabled people), developed by the ARMAROB research consortium. The FRIEND robot seeks to provide enhanced dexterous manipulation for people suffering from paralysis or other skeletal-muscular disorders (Volosyak, Ivlev, \& Graser, 2005).

While a number of robot advancements can directly mirror these types of teams, additional lessons can be learned. This type of exploration into the physical benefits to teaming can also provide insight into the scope of relevant and non-relevant behaviors, as well as provide additional insight into the mode of communication and type of feedback that may be important for naturalistic communication in this type of setting.

\section{Human-Animal Teams: Emotional Benefits}

A more recent goal to advance human-robot teaming relies on the integration of what Fong, Nourbakhsh, and Dautenhahn (2003) term, "human social" characteristics, or the "ability to express or perceive emotions, communicate with high-level dialogue, learn or recognize models of other agents, establish or maintain social relations, use natural cues (gaze, gestures, etc.), exhibit distinctive personality and character, and learn or develop social competencies" (pp. 145). A number of technical advancements have been made in the integration of human-like expression and perception of emotions (e.g., Kismet; Breazeal, 2000). However, there is still a need for the advancement of emotion-based characteristics (e.g., physical features, communication-based behaviors, and physical behaviors or actions) as we continue toward team-based interactions (see also Schaefer, Cook, Adams, Bell, Sanders, \& Hancock, 2012a). However, integrating human-like social and emotional characteristics is a difficult task, while not all advancements that incorporate emotional functions into robotic design need to, or even should, mirror human-like emotions, especially in the near-term development cycle.

Animals provide emotional benefits to human team members by providing comfort and companionship. Animals can also inform a person of their emotional capabilities and even augment emotional capabilities (see Fig. 2). The fields of social and therapeutic robotics have begun to leverage much of this work.

One of the most common human-animal relationships is that of companionship and comfort (e.g., pets). Companionship in these types of teams refers to animals that provide social support or comfort by reducing loneliness for their human counterparts (Staats, Wallace, \& Anderson, 2008). 


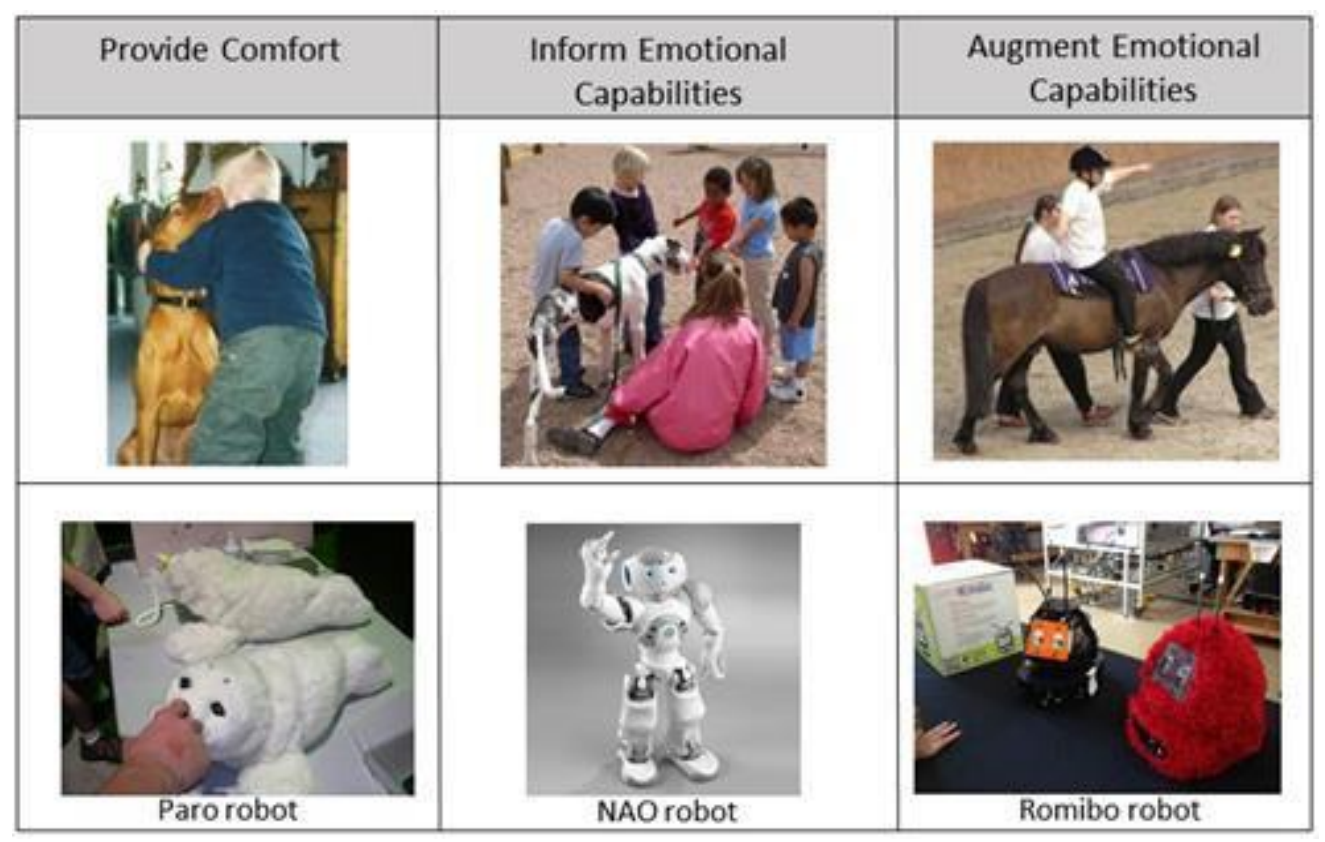

Figure 2. Emotional benefits of human-animal relationships

This, in turn, has a number of health-related benefits, including improved immunological and psychological functioning (e.g., decreased stress, anxiety, and blood pressure; Edwards \& Beck, 2002; Wesley, Minatrea, \& Watson, 2009; Yorke, Adams, \& Coady, 2008). Two key elements that come from exploring human-animal companionship are the importance of appearance and proximity. For example, some domesticated animals, such as cats and dogs, are specifically bred to produce 'cute' or attractive traits in order to facilitate instantaneous human-animal bonds that offer unconditional love and trust (Keaveney, 2008). Additionally, an animal's proximity to its human teammate may also impact a human's tendency to trust an animal. Such co-location has also been found to have an emotional effect on people interacting with domesticated animals, especially dogs and cats. Closeness allows pet owners to feel safe and comforted (Zasloff, 1996), which may in turn influence the evolution of trust development and build lasting trust (e.g., horse and rider; Keaveney, 2008).

The robotics industry is now starting to design a variety of systems that instill this level of companionship. Many socio-emotional robot designs are mirroring the physical form of animals. A relevant example here, in which robots are starting to provide similar emotional benefits to humans, includes Paro, a small seal-like robot designed to alleviate depression by providing companionship to elderly individuals (Subbaraman, 2013). Here, appearance is very important to design. The zoomorphic characteristics of animals (i.e., the attribution of animal characteristics, including physical appearance, to a machine) have also been found to impact trust (see Schaefer, 2013). People may use the appearance of an animal (or other entity) to assign that entity initial attributes, regardless of whether or not the attributes match the animal's true characteristics and capabilities (Upham Ellis et al., 2005).

Animals have also been used to edify or inform individuals of a deficiency in emotional capability. For example, the educational arena has been using animals to teach social skills, as well as work with individuals dealing with anxiety-inducing or abusive situations (Walsh, 2009). A child's interaction with an animal (e.g., brushing or petting, reading to the animal) can facilitate subsequent social behaviors, assist with disabilities such as dyslexia, reduce a child's perceived 
Phillips et al., Human-Animal Teams as an Analog

pain levels, improve self-esteem and self-acceptance, and enhance communication skills (see Fig. 2). For instance, research with the NAO robot was conducted for the purpose of using it to induce care-taking behaviors in children. Tanaka and Matsuzoe (2012) have investigated the utility of using social robots like NAO to encourage care-giving behaviors (e.g., teaching/instructing the robot on some skill), which in turn reinforces learning by teaching a paradigm. This paradigm allows children to gain deliberate practice with various skills by teaching those specific skills to a robot.

Human-animal teaming has also been used to augment emotional capabilities. Here, augmentation refers to situations in which humans and animals work jointly together, and through this interaction, the person is able to express some advanced emotional capability. For example, by providing enhanced levels of stimulation, therapeutic horseback riding, often referred to as hippotherapy, has been used to improve social functioning and directed attention in children, including those with autism spectrum disorder (Bass, Duchowny, \& Llabre, 2009). In the robotics domain, therapy robots like Romibo are similarly being used as therapy tools for children with autism and other autism spectrum disorders (Shick, 2013). The concept of augmented emotion within human-robot interaction is a recent theoretical construct that is only now beginning to be explored. Schaefer et al. (2012a) proposed that robots may provide an ideal mechanism for the concept of remote embodiment of emotions through "downloading emotions" (i.e., use robotic technology to provide more salient emotional cues of a person's emotions) or "emotional displacement" (i.e., fulfill an emotional void). Therapy through the use of robotic dolls is thought to improve mental functioning through activating rational thinking by imagining caring for the doll as one would a child (Yoshitaka, Masayoshi, Taro, Masaru, \& Tsuyoshi, 2012).

\section{Human-Animal Teams: Cognitive Benefits}

In the area of cognition, reaching human-like intelligence is a difficult problem. While a number of advancements have been made in cognition, including the development of cognitive architectures including Soar (Newell, 1990), ACT-R (Anderson \& Lebiere, 1998), and EPIC (Meyer \& Kieras, 1997), symbolic and subsymbolic generalizations are still needed (but difficult for computers) for more robust decision making (see Kelley \& Long, 2010). However, in teaming and interaction, the human oftentimes only needs to perceive the optimal intelligence level for a specific task. Therefore, it is important to be aware that the coupling of perception and action that impacts perceived intelligence (Brooks, 1999). Human-animal interaction provides the analogy for cooperation without the need for higher-level cognition (see also Sowa, 2006; Long \& Kelley, 2010).

Animals can provide humans with additional sensory information that can then be used by the team to make better, more informed decisions, especially in extreme environments where human sensory faculties are limited. However, human-animal teams vary greatly in the sophistication of their skill sets. For example, working canaries act as static sensors of the environment; while canines are able to independently act upon their environment and communicate information to their human teammates. Here, we describe how animals have been used to replace, extend, or even augment a human teammate's cognitive needs (see Fig. 3).

These animals are enhancing cognitive capabilities by providing additional sensory information that can be used subsequently to make more informed decisions. One way that animals fill this role is by prosthetically replacing cognitive capabilities, often by acting as sentinels used to detect risks to human team members. For instance, as late as the 1980's, canaries were still used as early warning detectors to provide British coal miners with a means to recognize the presence of poisonous gases within a mine, as the avian respiratory system is a more sensitive indicator of air quality and toxicity (BBC News, 1986; T. Clark, K. Clark, Paterson, Mackay, \& Norstrom, 1988). Nano UAV robots, such as the Black Hornet (Fig. 3), were used by British soldiers in Afghanistan to replace sensing capabilities needed for scouting and reconnaissance. Following a series of programmable waypoints, these tiny UAVs stream video imagery to their 


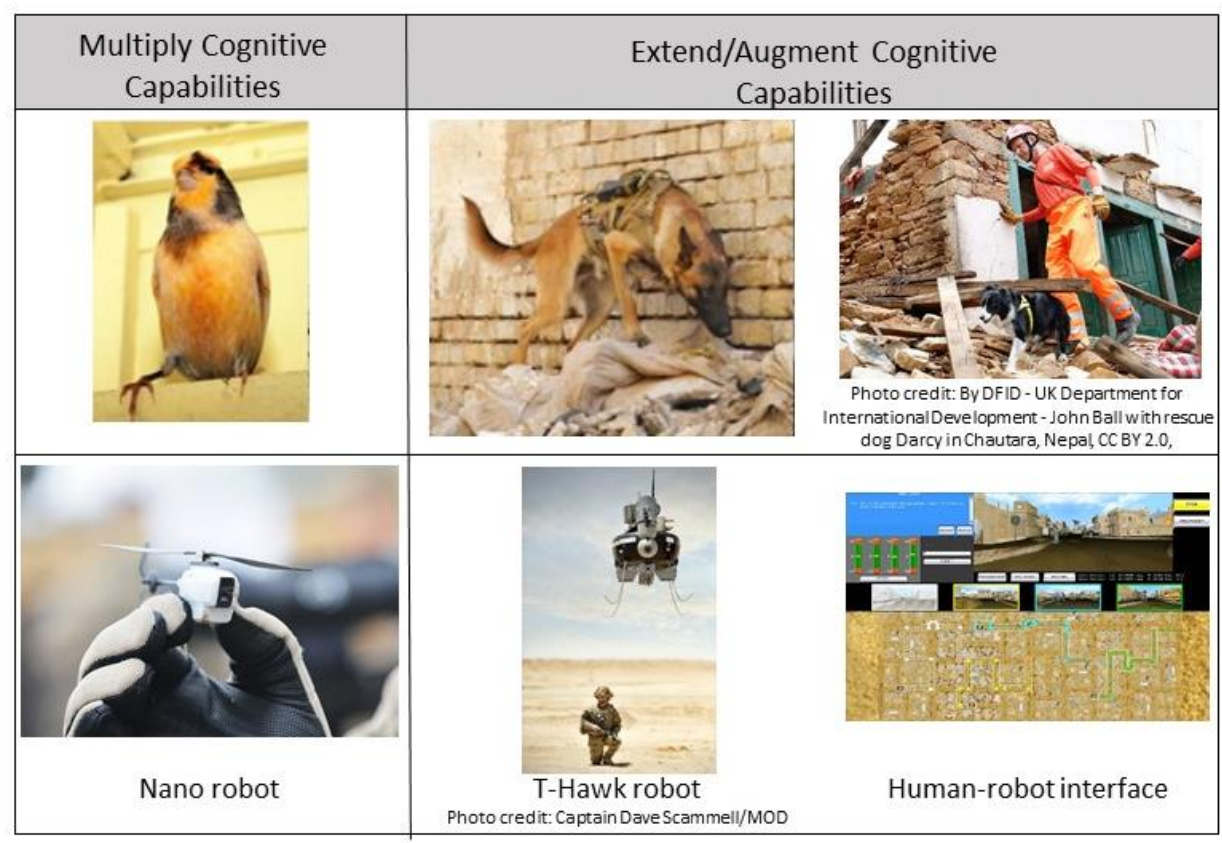

Figure 3. Cognitive benefits of human-animal relationships

human counterparts, thereby replacing the need to physically peer around corners or obstacles (Fincher, 2013).

A second type of human-animal team is used orthotically to extend or augment the human team member's cognitive reach by using the specific skills of an animal to assist in task completion. These include canine law enforcement, military working dogs (MWDs), sheepdogs, sled dogs, and specialist animals used in search-and-rescue (SAR) environments that exemplify human-animal relationships working in, and adapting to, difficult and dangerous environments (Finkel, 2012; Hancock, 1997; Helton, 2009). In extremely risky environments, the human handler's life and health may be in jeopardy if such human-animal interaction is unsuccessful. In many of these types of teams, animals are able to enhance the sensory capabilities of the team and enable better decision-making. For example, failure of a MWD to detect insurgents hiding in a warehouse may lead to a group of unsuspecting soldiers walking into an ambush. Similar robotic replacements are deployed in place of humans in dangerous environments. For example, robotic tools were used in the aftermath of the Fukushima nuclear disaster in Japan in early 2011. These robots helped officials maintain control over one of the nuclear reactors by providing a view of the damaged nuclear core in locales that posed a significant threat to human operators (Goldenberg \& McCurry, 2011).

A second type of human-animal team is used orthotically to extend or augment the human team member's cognitive reach by using the specific skills of an animal to assist in task completion. These include canine law enforcement, military working dogs (MWDs), sheepdogs, sled dogs, and specialist animals used in search-and-rescue (SAR) environments that exemplify human-animal relationships working in, and adapting to, difficult and dangerous environments (Finkel, 2012; Hancock, 1997; Helton, 2009). In extremely risky environments, the human handler's life and health may be in jeopardy if such human-animal interaction is unsuccessful. In many of these types of teams, animals are able to enhance the sensory capabilities of the team and 
enable better decision-making. For example, failure of a MWD to detect insurgents hiding in a warehouse may lead to a group of unsuspecting soldiers walking into an ambush. Similar robotic replacements are deployed in place of humans in dangerous environments. For example, robotic tools were used in the aftermath of the Fukushima nuclear disaster in Japan in early 2011. These robots helped officials maintain control over one of the nuclear reactors by providing a view of the damaged nuclear core in locales that posed a significant threat to human operators (Goldenberg \& McCurry, 2011).

\section{The Relationship to Trust}

As robots take on roles of integrated team members (presumably without human-level intelligence-competence), the issue of trust becomes a major concern (Hancock et al., 2011a). Not only does trust determine when and how much a user will rely on a particular system (Lee \& See, 2004), it impacts the degree to which a human teammate is willing to accept contributions from a robot (e.g., sensory data, information to assist in decision-making, suggestions for courses of action). Thus, the human may potentially fail to take advantage of the inherent robotic system benefits (Freedy, de Visser, Weltman, \& Coeyman, 2007). For this reason, trust is especially critical when it comes to decision-making in high-risk environments, such as military combat missions (Park, Jenkins, \& Jiang, 2008).

Similarly, as trust mediates human-automation relationships (Sheridan, 1975; Sheridan \& Hennessy, 1984), it also mediates human-animal relationships. Therefore, a human's trust in a non-human teammate is a necessary requirement to ensure that any functional relationship will ultimately be effective regardless of domain, environment, or task. Here, we provide a brief review revealing how humans learn to trust animals, in order to describe possible analogs for humanrobot teams. For a more in-depth qualitative review on human-animal trust, we refer the reader to two extended technical reports: Billings et al. (2012) and Phillips, Ososky, Swigert, Grove, and Jentsch (2010).

In general, trust exists prior to any interaction (Sheppard \& Sherman, 1998). This principle also holds true for human-animal relationships. A person draws conclusions about the attributes, personality, capabilities, and level of intelligence of that animal, regardless of whether or not they are true characteristics, behaviors, or capabilities (see Upham Ellis et al., 2005; Helton, 2010; Finkbeiner et al., 2014). These linkages are also found in HRI and are discussed in terms of influence on the initial trustworthiness of a partner, animal, machine, or robot (Schaefer, 2013). What can be drawn from this discussion is that the shape or physical form not only matters, but it can impact initial trustworthiness of a partnership. Therefore, considerations should be made in the robot's physical form design.

Trust also develops and changes during an interaction. In other domains, this is called either cognition-based trust (Burke, Sims, Lazzara, \& Salas, 2007; McAllister, 1995) or history-based trust (Merritt \& Ilgen, 2008). This type of trust is influence by both capabilities of the animal and predispositions of the person. Specific to animal capabilities, predictability of behavior appears to be key in the development of a trusted relationship. For example, trust can be influenced by the animal's ability to follow instructions given by the human (Pepe, Ellis, Sims, \& Chin, 2008). Additionally, awareness also appears to play an influential role in trust development, in that determining or predicting the animal's behavior in different circumstances and interpreting one's own capabilities in response to the animal's behaviors is important. In human interpersonal teams, this is referred to as directed and reflected knowledge (Mortensen \& Neeley, 2012).

For instance, a dog handler must be continually aware of potential dangers in the environment as well as the animal's obedience and predictability in those different dangerous scenarios (Sanders, 2006). Yet, people will often still hold predisposed mistrust against the animal, no matter how much the animal has been domesticated or trained (Keaveney, 2008). In other words, even though their experiences with animals can be positive, humans still hold beliefs that animals will exhibit behavior characteristically associated with that particular animal (e.g., a horse will act like a horse and bolt). However, it has also been shown that mutual trust can only occur after an 
established means of communication and respect between the two entities has developed. Due to the importance and impact of communication, a more in-depth description of communication and its relationship to trust is provided in a later section here. Trust also changes over time, based on the history of prior interactions. According to Wilson (1994), past experiences with animals serve as indicators of future relationships. If experiences were largely positive, the likelihood of future interactions with the same or similar animals may be greater than if experiences had been predominately negative. These prior experiences were found to be related to trusting animals. For a successful partnership to occur, humans must spend time with their animals each day, thereby enabling them to predict how that animal will react to most situations. This is crucial to the development of an understanding of the animal (Robinson, 1999). This is especially relevant for interaction in high-risk environments. Trust plays the greatest role in contexts where there are high levels of uncertainty and risk and a lesser role in situations that are non-threatening and predictable (Miller, 2005). In effect, the type of human-animal partnership will dictate the levels of risk involved in the interaction. As such, the role of situational trust in a human-pet relationship is much lower, due to the low amount of risk involved, than the trust involved in a human-animal interaction occurring in dangerous (e.g., riding a horse) or life-threatening environments (e.g., subzero temperatures), due to high levels of uncertainty and risk. For example, dogsled patrols require humans to rely on their dog team in highly remote Arctic locations, where hunger, life-threatening injuries, exhaustion, frostbite, and threats from predators are extremely likely (Finkel, 2012). Further, the extent to which a human must rely on an animal in order to perform specific tasks or to extend their capabilities (e.g., guide dog for the blind) can impact the degree of trust the human must have in order to interact most effectively. Essentially, the riskier the situation is, the more important human-animal trust becomes, as sometimes a human must rely solely on the decisions of their animal partner (e.g., sled-dog and human partnership during a bad storm in a secluded area; Kuhl, 2008).

Therefore, the amount of training a human and their animal partner undergo before interacting impacts trust in the human-animal relationship. For a respectful partnership to develop, both the human and the animal partner should be trained appropriately (Greenebaum, 2010). For example, the amount of training horse owners have with their horse influences their ability to relate with, understand, and trust them (Keveaney, 2008). This may also be the case with human-animal partnerships with pets, service animals, etc. For example, it has been demonstrated that consistent interaction with a therapy animal can lead to the development of trust in that animal. This can transfer (over time) to interactions with people (Wesley et al., 2009). Thus, training reinforces any relationship between humans and animals.

Techniques individuals employ when training animals are reflections of their specific perceptions (Greenebaum, 2010), or mental models, of human-animal relationships. Since humans are socially inclined, they tend to automatically respond to social cues (Lee \& Kiesler, 2005) that generate estimates of a system's, or in this case, an animal's, abilities and overall performance. Through training, animals develop an understanding of human body language, and vice versa. As a formal interaction, training not only socializes an animal into its role as either a family member or a teammate, but it also highlights the responsibilities of the trainer (Greenebaum, 2006-2007). In turn, the socially-constructed status of the animal (companion, teammate) and of the human (owner, guardian) will influence training methods (Sanders 1999; 2006; Greenebaum 2004; Irvine 2004) and the human-animal trust relationship. Certain training techniques, such as reward-based training (behavior modification), establish trusting relationships (Greenebaum, 2010) and mutual respect between human and animal. As trust is a two-way process, it requires both parties to engage in ways that support a respectful partnership.

Guided by trust, humans rely on animals for their judgment, skills, and obedience, while animals rely on humans for guidance and care. Using this knowledge to develop zoomorphic robotic teammates may be advantageous, because it will build on the mental models people already possess about human-animal training relationships. For instance, robots and teammates may be able to build trusting relationships in settings where each entity is learning new skills. This 
Phillips et al., Human-Animal Teams as an Analog

may provide an opportunity for each to become familiar with the other's abilities and tendencies as they work through tasks together. Researchers have noted that the most important requirements for developing what will ultimately be human-robot interactions that resemble teammate interactions are system trust and the ability to predict system behavior (Marble, Bruemmer, Few, \& Dudenhoeffer, 2004). As such, establishing a training relationship between humans and their future robotic partners may help to provide a basis upon which an understanding of robot capabilities and limitations can be formed and trusting relationships can be established.

\section{Factors Involved in Human-Animal Teamwork}

Current human-animal teams are capable of accomplishing a variety of complex tasks and providing a range of benefits to humans. It is important to understand the behaviors and capabilities such teams exhibit, as they can be used to model the capabilities needed to support near-future human-robot teaming. While reviewing existing human-animal teams, two factors associated with teamwork proved prominent and widespread. These were task interdependence and communication, both of which are predicated on trust.

\section{Task Interdependence}

Task interdependence is the "degree to which group members must rely on one another to perform their respective tasks effectively" (Saavedra, Earley, \& Van Dyne, 1993, p. 61). This may take the form of initiated (i.e., work progresses from a particular unit or job to another job), or received (i.e., the degree to which one job is affected by the progression of work from another job) task interdependence (Kiggundu, 1981). Initiated interdependence is determined by providing outputs to another group, team, or individual team member within the work environment, while received interdependence is determined by the receipt of workflow outputs from another entity in the work environment.

Additionally, task interdependence can be described as pooled, sequential, or reciprocal in its nature. In pooled interdependence teams, members complete their work separately, there is a low level of direct interaction between individuals, and the summation of their individual contributions dictates successful team performance (Saavedra et al., 1993). As such, each member of a pooled interdependence team initiates and receives low interdependence. In sequentially interdependent teams, each member carries out their roles in a pre-defined sequence, requiring that each step be performed efficiently and in the correct order. On the other hand, reciprocal task interdependence is characterized by a distinct, externally imposed role structure within the group, in which each member has a certain expertise or specialization. Additionally, the sequence in which sub-parts of a task are carried out can be conducted in a flexible order.

The distinctions made between pooled, sequential, and reciprocal interdependence also represent increasing needs for coordination between individual team members and reliance on others for successful job performance. For successful team performance, more coordination between individual team members is needed in sequentially interdependent teams than in teams with pooled interdependence. Similarly, more coordination between individual team members is needed in reciprocally interdependent teams than in sequentially interdependent teams (Thompson, 1967, as cited in Saavedra et al., 1993). As described by Thompson (1967), these "three patterns of work flow ... each represent a different intensity or degree of linkage between units" (p.486). The distinctions between pooled, sequential, and reciprocal interdependence can be used to classify various human-animal teams, where teammate-like relationships are characterized by increasingly reciprocal interactions.

According to interdependence theory as described by Victor and Blackburn (1987), the relationship between members of a work unit can be described by the requirements for joint activity as dictated by the workflow in the team, requirements for one's own actions, and requirements for the actions of others. These three requirements give individuals in interdependent 
Phillips et al., Human-Animal Teams as an Analog

Team asked to locate narcotics in an area

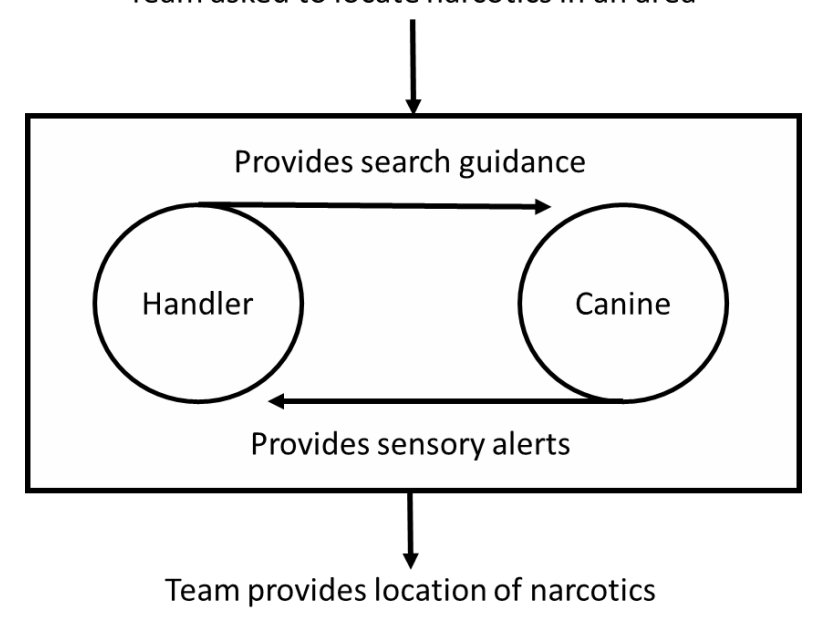

Figure 5. Reciprocal task interdependence in a human-canine narcotics search team

teams a degree of control (either absolute or contingent) over the performance of the team. More specifically, "the amount of interunit interdependence is defined as the extent to which a unit's outcomes are controlled directly by or are contingent upon the actions of another unit" (Victor \& Blackburn, 1987, p. 490).

A human-canine narcotics search team is an excellent example of reciprocal human-animal interdependence teaming in which the outcomes of the team are controlled by each member's independent actions. In this team, the human team member generally guides the dog through an overall search area, relying on the dog's superior olfactory senses to perform a detailed search. The dog relies on the human handler for overall direction and guidance, alerting the handler when narcotics are detected. The handler then informs others that narcotics have been detected, and the human-canine team moves to a different search area to repeat this process (Dark Knight K9 Detection, n.d.). As an iterative process, each team member performs a specific function based on their individual expertise, the order in which each function is carried out is constantly alternating between the two respective team members, and the degree to which the outcome of one member is reliant on the other (and vice versa) is high. As such, the success of this team is highly contingent upon the work accomplished by each entity alone as well as the way in which the work alternates in the two-way interaction between entities.

Each member of the human-canine narcotics search team is characterized by both highinitiated and high-received interdependence. In other words, both the human and the canine team members provide an equally high number of outputs to the other. For the human, these outputs are in the form of commands, navigational search guidance, and high-level handling and care for the canine. The canine produces outputs in the form of superior search capability, sensory alerts to the presence of narcotics, or the absence of sensory alerts when narcotics are not present. Both members receive equally high outputs from the other. The human team member's outputs become the canine's inputs and vice-versa, thus controlling the reciprocal nature of the team's interdependence (see Fig. 5).

Finally, it is important to note that human-animal team analogs of interdependence teaming are pertinent means to illustrate that full human emulation is not necessary to facilitate meaningful 


\section{Pooled Interdependence Team}

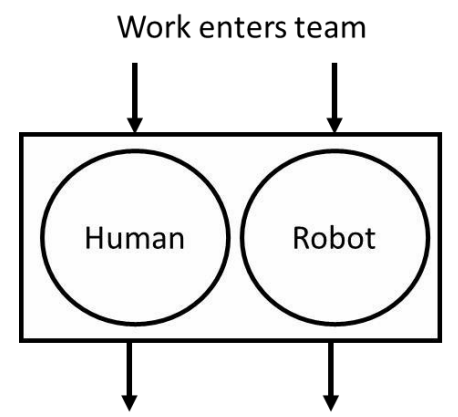

Work leaves team

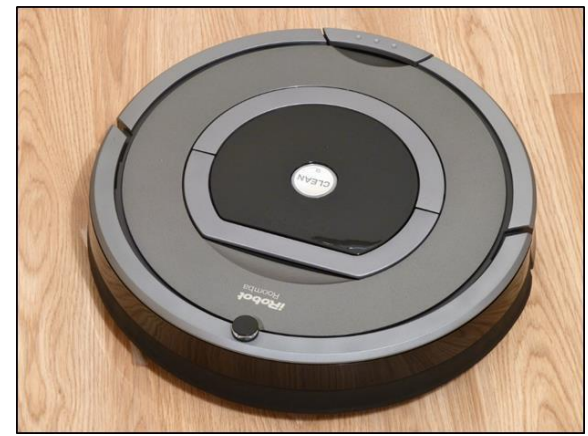

Figure 6. Example of pooled interdependence human-robot interaction.

human-robot teamwork. In fact, researchers suggested that full human emulation in human-robot interaction is a somewhat misguided approach, as it ignores the skills that robots can uniquely contribute to a team. For example, Groom and Nass (2007) have suggested that "in the struggle to make robots into people, researchers have not fully identified the human characteristics that robots lack nor have the robot characteristics that humans lack... Researchers sometimes overlooked what makes robots special" (p. 494). They go on to suggest that human-robot teamwork is best facilitated through an approach in which the skills of robots complement the skills of humans, not unlike the ways in which humans and animals leverage skills to work interdependently and complete a wide variety of work.

In addition, relevant examples of teaming that vary in level of task interdependence can be found in the existing robotics domain. For instance, the Roomba, by iRobot, operating in a household is an example of pooled interdependence between humans and robots (see Fig. 6). While completing household cleaning tasks, the robot is specialized in its ability to complete household work. Therefore, the human and the robot complete separate tasks. It is the summation of each member's work that dictates how well the task is performed.

Sequential interdependence of human-robot interaction can be seen in manufacturing settings. Manufacturing often uses robots, and robotic technologies, for tracking and moving individual components and parts (see Fig. 7). These automated entities help to route parts through the machining sequence necessary to ensure that parts are tooled accurately and in the correct order (Monette, Corriveau, \& Dubois, 2007). In this type of interaction, human and robot team members carry out separate task components. However, the order in which the tasks are completed is important to ensure that the task is performed well. 


\section{Sequential Interdependence Team}

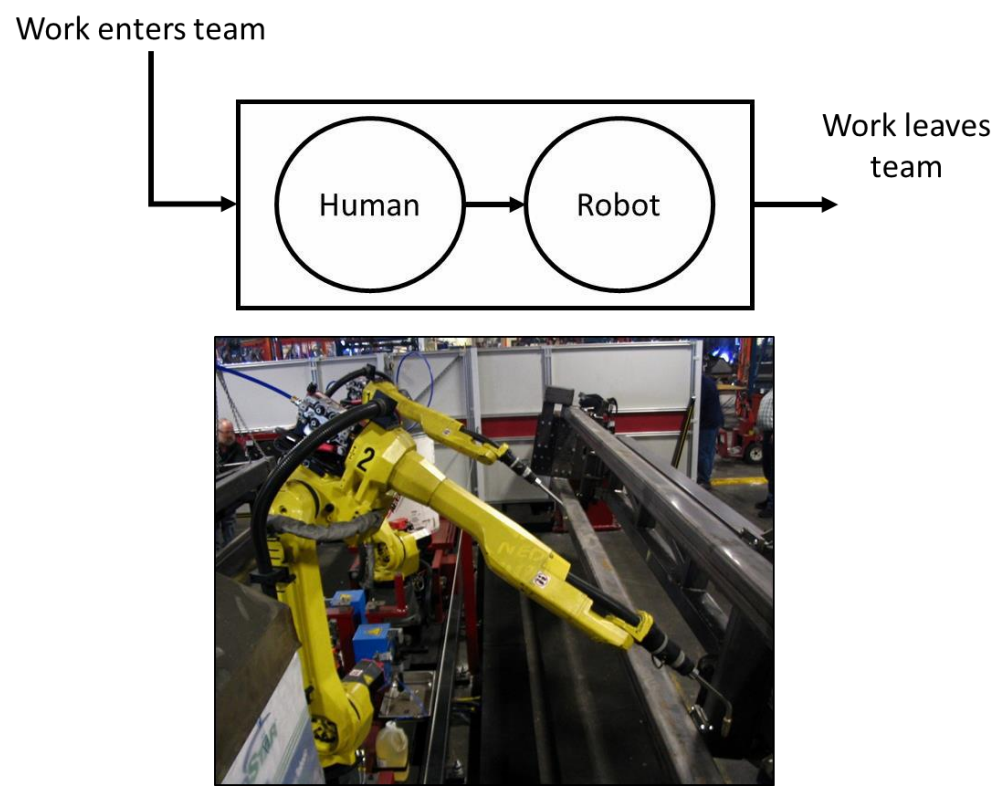

Figure 7. Example of sequential interdependence human-robot interaction

Finally, reciprocal interdependence can be seen in command and control settings where a human operator is capable of controlling multiple robots (see Fig. 8). Command and control of multiple robots is often seen in military-type tasks and is not moving into a number of civilian realms. In many of these settings, human(s) and robot(s) reconnoiter important areas. The human is responsible for overseeing the tasking of the $\operatorname{robot}(\mathrm{s})$. Subsequently, while the $\operatorname{robot}(\mathrm{s})$ autonomously carry out their tasks, they periodically send information about task completion back to the human. The human, then, decides the next course of action, whether it be to re-task the robot(s) or to adjust the tasking of the robot(s). This type of interaction is reciprocal in nature; the human maintains high-level oversight of the robot(s), and based on the information provided by the robot(s), decides the next course of action for the team. Reciprocal exchange of information between team members dictates task completion.

\section{Communication}

Team communication is also a prominent and widespread feature of human-animal teaming. Team communication is central to interaction and coordination. It requires both the transfer of information from one partner to another and the use of commands and requests to gain information when needed. The most common forms of communication seen in human-animal teams involve auditory and visual communication styles, such as verbal commands and body language. Other sensory communication forms, such as scent, are less commonly used to convey needs; however, they can communicate intentions toward the animal (The Hunting Dog, 2008; Meredith, n.d; Yeon, 2007). Certain communications are based on the degree of auditory and body language used when both the human and animal engage in a task together. Higher amounts of communication result in greater understanding of each team member's needs and intentions; teams that employ more communication across a variety of modalities exhibit higher levels of teaming than those exhibiting less communication. 


\section{Reciprocal Interdependence Team}

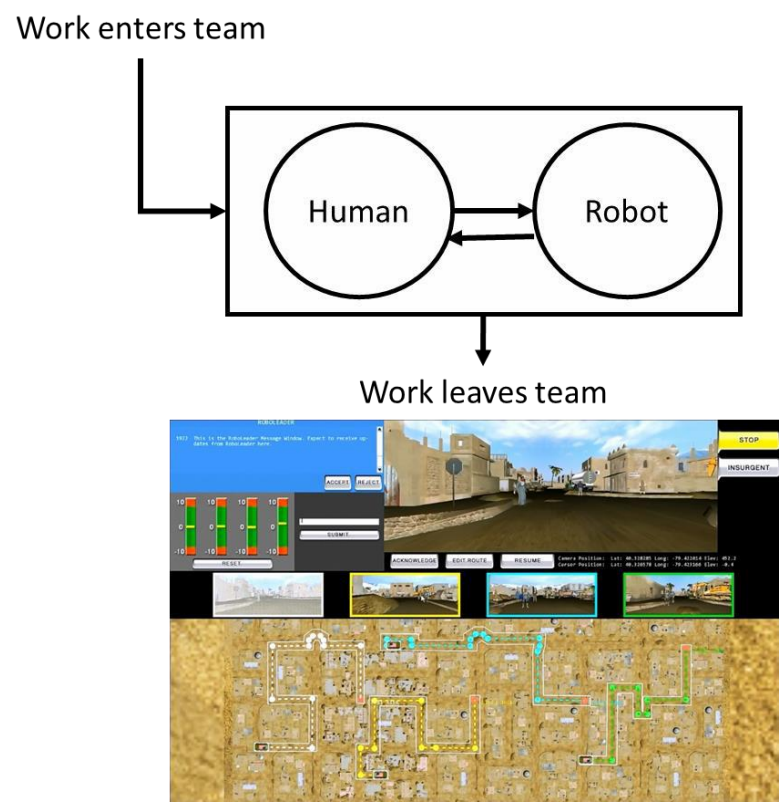

Figure 8. Example of reciprocal interdependence human-robot interaction. Figure depicts conceptual representation of a command and control interface for interacting with multiple robots.

The amount of communication in human-animal teams is mostly animal dependent and can be directional or reciprocal contingent upon the animal's capacities. For example, low levels of communication are seen in harness teams, where the animal is primarily used for its endurance and strength (e.g., oxen plowing fields or donkeys and mules transporting goods). Communication is directional in these teams. The human team member initiates commands (e.g., "Gee," "Haw," "Whoa") which relay intention to the animal. The animal partner receives commands and executes orders without overtly communicating back to their human teammate ("Oxen Team Practice," 2010; Russell, 2008). In these types of teams, animal communication with the human teammate is often limited to compliance with the order.

On the other hand, animals such as dogs or horses have natural abilities to provide auditory and visual communication to their human handler, as well as interpret and attribute meaning to the human team member's verbal (e.g., speech, clicks, utterances, inflection) and nonverbal communication (e.g., body posture, pressure, gestures). The increased communication capabilities of these animals are often demonstrated in sporting events, such as horse racing, dog obedience tests, hunting games, and sheep-dog trials (see The Hunting Dog, 2008; Goodwin, 1999; Hancock, 1997; Hancock, 2009; Meredith, n.d.). For example, a canine will communicate intentions and needs through barks, whines, and growls when vocalizing. Canines may also signal to the human through gestures by the head and tail, the position of their legs, and other types of postures and movements that might be employed when communicating with another dog; pointing for instance (The Hunting Dog, 2008; Dodman, n.d.; Simpson, 1997). These types of teams are characterized by a communication style in which both parties equally participate in outward vocalization as well 
as gestural, nonverbal communication (Helton, 2009). Together, this bi-directional or reciprocal communication appears to be most similar to natural human-human communication. This reciprocal form of communication also involves speech-related and speech-independent gestures (Knapp \& Hall, 2010).

For many contexts, the implementation of the type of rudimentary communications in many human-animal teams may be overly simplistic, given that the state of the art in robotic and other autonomous technologies is, indeed, capable of more complex semantic language understanding between humans and robots (Kollar, Tellex, Roy, \& Roy, 2010). However, for other contexts (such as military contexts), more simplistic forms of communication (e.g., gestures, simple verbal commands) will be beneficial in supporting teaming that can generalize to a variety of missions and contexts, especially contexts in which team members need to communication quickly, over long distances, or in instances of stealth operations. Rudimentary communications that can be efficiently conveyed through multiple modalities, such as hand signals or constrained natural language vocalizations, could be more effective during these types of missions. For these reasons, there has been a push in the human-robot interaction community to support this type of efficient bi-directional communication for military human-robot teams (Barber, Lackey, Reinerman-Jones,

\& Hudson, 2013; Lackey, Barber, Reinerman, Badler, \& Hudson, 2011; Phillips, Rivera, \& Jentsch, 2013).

Understanding existing human-animal teams' communication and the degree to which each team member's role is interdependent with the other can help us to better understand the degree to which these teams resemble effective human-interpersonal teams. Although the ability to design robots with communication and interaction capabilities as complex as human or working dogs is not yet fully realized; other human-animal teams provide a good analog for building robotic capabilities that, while they may be less complex than human capabilities, still can be leveraged to accomplish many types of work. If the ability to create a robotic partner that replicates a human partner is not yet available, then the next best capacity may be to create a robotic teammate that resembles an animal partner.

\section{The Relationship to Trust}

Examining the nature of trust in human-animal relationships can increase our understanding of how humans interact with certain technology, such as automation, autonomous systems, or robots. It involves three separate notions: (1) knowing how a partner will respond, (2) trusting oneself to interpret a partner's behavior, and (3) trusting oneself to communicate. In these relationships, the human needs to trust that their animal partner will do the task it was trained to perform. However, the human must also understand that at times, the animal will also act like an animal, displaying tendencies and behaviors that are based upon their particular instinctive reactions. For example, according to the "human-horse mutual trust paradigm," a rider must trust their horse to protect them while mounted, but also understand that their horse could break from their predictable role and "act like a horse," shying away from the owner, galloping off, or responding to a frightening stimulus (Keaveney, 2008).

Applying known information about human-animal teaming (e.g., level of interdependence, communication structure) to robotic partners may be means by which humans can begin to build trusting relationships with robots. Human teammates will be able to draw upon well-established mental models that also assist in trust development with animal partners. The means by which communication is accomplished in human-animal teams may be one model by which this understanding can be fostered and mutual trust can be formed in human-robot teams.

Communication within human-animal work teams is very important; a human must understand the animal, interpret its behavior, and possess the ability to communicate commands effectively to the animal (Kuhl, 2011). Each partnership is unique, in part due to each animal 
Phillips et al., Human-Animal Teams as an Analog

having a distinctive quality or style of expression, and each human may interpret that expression differently. Therefore, trust can only occur after an established means of communication and respect between the two entities has been developed (Oma, 2010; Sanders, 2006). This occurs through frequent interaction and training. In terms of specific application to human-robot interaction, future research should explore the costs and benefits of introducing robots capable of emulating respect and trust for their human counterparts.

The type and level of interdependency in human-animal teams can also help us better understand how trust is formed in human-robot teams. The human teammate must be willing to trust and accept the information being supplied by the animal (or robot, as the case may be) as accurate and correct. Likewise, the human must trust that the animal is performing its part of the job competently, as trained. Interdependent work inherently requires team members to function in tandem, relying on each other to provide a specific piece of the overall picture. If a human teammate refuses to trust the information or work of his non-human counterpart, the team becomes inefficient. We therefore conclude that our understanding of human-robot interactions can be improved by drawing on comparisons with human-animal partnerships (Coeckelbergh, 2011).

\section{Conclusions: Leveraging Metaphors to Inform HRI}

Relationships with animals are prevalent in most human societies. Existing human-animal teams range widely in the degree to which animal partners act more as interactive teammates rather than animate tools. Further, such teams are used to accomplish a wide variety of human-animal tasks. Animals may be good analogs for robots, because even the most "tool-like" of existing teams show more autonomy than state-of-the-art teleoperated robots. Many roles animals fill in humananimal teaming parallel existing and future roles of robots in human-robot teams. Many humananimal interactions show work interdependence and communication patterns that are similar to interpersonal teams. As such, existing human-animal teams serve to provide insight into a wide range of intelligence and autonomy analogues from which robotic designers can take inspiration. The widespread capabilities that support this type of teamwork can potentially be used as a tool to guide the instantiation of working animal characteristics into robotic entities.

We may be able to start by modeling simpler (more tool-like) human-animal teams and progress to more complex teams as technology itself progresses. For instance, many humananimal teams can accomplish a wide range of tasks with limited vocabularies and communication abilities (Hancock, 1997; Phillips et al., 2012; Phillips, Rivera, \& Jentsch, 2013). In spite of a limited communication bandwidth, humans and animals have been able to use this limited communication 'vocabulary' to accomplish meaningful work for many centuries and even millennia. Drawing on and expanding upon this vocabulary to develop a useful taxonomy may be possible for further understanding and predicting future human-robot teams' behavior, especially for envisaged military contexts.

We have argued that forms of nonverbal communication in robots help humans to understand why robots behave as they do, making robot behavior more transparent to humans (Breazeal, Kidd, Thomaz, Hoffman, \& Berlin, 2005). By drawing on communication and interaction methods that are already meaningful to humans, we can start developing robots that resemble interactive partners that draw upon well-established mental models. This transfer is beneficial, as it helps humans to form expectations about their technological teammates that are appropriate to the robot and slowly develop as robots become more sophisticated over time.

Trust is an essential dimension for building effective interactions between future human-robot teams, as trust ensures that functional relationships between humans and robotic teammates can be formed and sustained (Hancock et al., 2011a, 2011b; Schaefer, 2013). A trusting relationship 
Phillips et al., Human-Animal Teams as an Analog

between humans and animals depends on cooperation, the ability to predict behavioral successes and failures, and establishing a joint communication paradigm. The ability to simulate these in a robotic entity will be a large step forward in developing trusting and effective partnerships between humans and robotic teammates. These and prior observations on trust tend to beg anthropomorphic questions. If indeed, human-animal teams are the metaphor for future HRI, should we build robots that are specifically co-dependent on their users? That is, should we seek to design, create, fabricate, and include all the problems and shortcomings of living systems into the robot surrogate? Some might say that this defeats the whole purpose of robots in the first place. After all, they are artificial machines with all of the potential advantages that such non-living, insensate dimensions bring (e.g., no fear of danger, non-experience of pain, etc.). However, if they emanate no empathy at all and are not appropriately responsive to their user, they may be in danger of misuse, disuse, and abuse. It is a design conundrum that the human-animal team analog identification brings to the fare. The underlying master-servant structure may, however, become quickly obsolete as autonomous robots gain agency, self-awareness, and superior capabilities.

\section{Key Points}

The study of working animals, their capabilities, the ways in which trusting relationships are formed with animal partners, and our interactions with them, all provide additional insights into how to design future robotic teammates. To this end, the following propositions can be generated:

- Human-animal relationships represent a unique form of partnership that can often directly benefit the human physically, emotionally, and cognitively. Robotic technologies are beginning to take a surrogate role in benefiting human partners in similar ways. However, additional gains can be made.

- Human-animal teams range in degrees of interdependence and complexity with which they communicate with one another to accomplish work. If the goal is to foster humanrobot relationships that resemble human-human teammates, modeling these capabilities (like human guidance in reciprocal interdependent human-canine teams) can represent a logical progression in the development of better human-robot teaming.

- Trust will ultimately determine how human users interact with their robotic teammates. Thus, the means by which trust is fostered in analogous human-non-human teams serves as a crucial template for fostering trusting relationships in human-robot teams.

\section{Acknowledgements}

The research reported was performed in connection with contract number W911NF-10-2-0016 with the U.S. Army Research Laboratory. This research was also supported in part by an appointment to the U.S. Army Research Postdoctoral Fellowship Program administered by the Oak Ridge Associated Universities through cooperative agreement W911-NF-12-2-0019 with the U.S. Army Research Laboratory. The views and conclusions contained in this document are those of the authors and should not be interpreted as presenting the official policies or position, either expressed or implied, of the U.S. Army Research Laboratory, or of the U.S. Government, unless so designated by other authorized documents. Citation of manufacturer's or trade names does not constitute an official endorsement or approval of the use thereof. The U.S. Government is authorized to reproduce and distribute reprints for government purposes notwithstanding any copyright notation herein. The authors would also like to acknowledge the various research assistants and support staff associated with the generation and submission of this document. 


\section{References}

Ackerman, E. (2014). Robot octopus takes to the sea. IEEE Spectrum. Retrieved from http://spectrum.ieee.org/automaton/robotics/robotics-hardware/robot-octopus-takes-to-the-sea

Americans With Disabilities Act of 1990, C.F.R.§ 36.104 (2002).

Anderson, J. R., \& Lebiere, C. (1998). The atomic components of thought. Mahway, NJ: Lawrence Erlbaum Associates.

Army Research Laboratory (2011). Robotics Collaborative Technology Alliance (RCTA) FY 2011 annual program plan. Retrieved from

http://www.arl.army.mil/www/pages/392/rcta.fy11.ann.prog.plan.pdf

Balch, T., \& Arkin, R. C. (1995). Motor schema-based formation control for multiagent robot teams. In Proceedings of the $1^{\text {st }}$ International Conference on Multiagent Systems (ICMAS) (pp. 10-16). AAAI, San Francisco, CA

Barber, D., Lackey, S., Reinerman-Jones, L., \& Hudson, I. (2013, May). Visual and tactile interfaces for bi-directional human robot communication. In Proceedings of the 2013 SPIE Defense, Security, and Sensing: Unmanned Systems Technology XV (Vol. 8741). Baltimore, MD: SPIE. doi:10.1117/12.2015956

Bass, M. M, Duchowny, C. A., \& Llabre, M. M. (2009). The effect of therapeutic horseback riding on social functioning in children with autism. Journal of Autism and Developmental Disorders, 39(9), 1261-1267. doi:10.1007/s10803-009-0734-3

BBC News. (1986). Coal mine canaries made redundant. Retrieved from http://news.bbc.co.uk/onthisday/hi/dates/stories/december/30/newsid_2547000/2547587.stm

Billings, D. R., Schaefer, K. E., Chen, J. Y. C., Kocsis, V., Barrera, M., Cook, J., Ferrer, M., \& Hancock, P. A. (2012). Human-animal trust as an analog for human-robot trust: A review of current evidence (Tech. Rep. No. ARL-TR-5949). Aberdeen Proving Ground, MD: U.S. Army Research Laboratory.

Blumberg, B., Downie, M., Ivanov, Y., Berlin, M., Johnson, M. P., \& Tomlinson, B. (2002). Integrated learning for interactive synthetic characters. In Proceedings of the $29^{\text {th }}$ Annual Conference on Computer Graphics and Interactive Techniques (SIGGRAPH) (pp. 417426). New York, NY: ACM. doi:10.1145/566654.566597

Boston Dynamics. (2013). BigDog-The most advanced rough-terrain robot on earth. Retrieved from: http://www.bostondynamics.com/robot_bigdog.html

Breazeal, C. L. (2000). Sociable machines: Expressive social exchange between humans and robots. Cambridge, MA: Massachusetts Institute of Technology.

Breazeal, C., Kidd C. D., Thomaz, A. L., Hoffman, G. \& Berlin, M. (2005). Effects of nonverbal communication on efficiency and robustness in human-robot teamwork. In Proceedings of the 2005 Conference on Intelligent Robots and Systems (IROS) (pp.708-713). Barcelona: IEEE. doi:10.1109/IROS.2005.1545011

Brooks, R. A. (1999). Cambrian intelligence: The early history of the new AI. Cambridge, MA: Massachusetts Institute of Technology.

Burke, C. S., Sims, D. E., Lazzara, E. H., \& Salas, E. (2007). Trust in leadership: A multi-level review and integration. The Leadership Quarterly, 18, 606-632. doi:10.1016/j.leaqua.2007.09.006

Clark, T., Clark, K., Paterson, S., Mackay, D., \& Norstrom, R. J. (1988). Wildlife monitoring, modeling, fugacity: Indicators of chemical contamination. Environmental Science and Technology, 22(2), 120-127. doi:10.10201/es00167a001 
Phillips et al., Human-Animal Teams as an Analog

Coeckelbergh, M. (2011). Humans, animals, and robots: A phenomenological approach to humanrobot relations. International Journal of Social Robotics, 3, 197-204. doi:10.1007/s12369-010-0075-6

Dark Knight K9 Detection Agency (n.d.). Retrieved from http://www.darkknightk9.com/FAQ.html

Dodman, N. (n.d.). Dog to dog communication. Retrieved from http://www.petplace.com/dogs/ dog-to-dog-communication/page1.aspx

Edwards, N. E., \& Beck, A. M. (2002). Animal-assisted therapy and nutrition in Alzheimer's disease. Western Journal of Nursing Research, 24(6), 697-712. doi:10.1177/019394502320555430

Fincher, J. (2013, February). Handheld black hornet nano drones issued to U.K. soldiers. Gizmag. Retrieved from http://www.gizmag.com/black-hornet-nano-uav/26118/

Finkbeiner, K. M., Russell, P. N., \& Helton, W. S. (2014). Rating of dog breed differences insights for quadropedal robot design. In Proceedings of the Human Factors and Ergonomics Society Annual Meeting, 58(1), 581-585., Chicago, IL.

Finkel, M. (2012). The cold patrol. National Geographic, 221(1), 82-95.

Fong, T., Nourbakhsh, I., \& Dautenhahn, K. (2003). A survey of socially interactive robots. Robotics and Autonomous Systems, 42 (3-4), 143-166. doi:10.1016/S09218890(02)00372-X

Freedy, A., de Visser, E., Weltman, G., \& Coeyman, N. (2007). Measurement of trust in humanrobot collaboration. In Proceedings of the 2007 International Conference on Collaborative Technologies and Systems (pp. 106-114), Orlando, FL. IEEE. doi:10.1109/CTS.2007.4621745

Gannes, L. (2014, May 27. Google's new self-driving car ditches the steering wheel. Retrieved from: http://recode.net/2014/05/27/googles-new-self-driving-car-ditches-the-steering-wheel

Genter, D., \& Holyoak, K. J. (1997). Reasoning and learning by analogy: Introduction. American Psychologist, 52(1), 32-34. doi:10.1037/0003-066X.52.1.32

Goldenberg, S. \& McCurry, J. (2011, March). Japan nuclear plant gets help from U.S. robots. The Guardian. Retrieved from http://www.guardian.co.uk/world/2011/mar/29/japan-nuclearplant-us-robots

Goodwin, D. (1999). The importance of ethology in understanding the behavior of the horse. Equine Veterinary Journal Supplement 28, 15-19.

Greenebaum, J. B. (2004). It's a dog's life: Elevating status from pet to "fur baby" at yappy hour. Society and Animals, 12(2), 117-135. doi:10.1163/1568530041446544

Greenebaum, J. B. (2006-2007). The throw-away society and the family dog: An exploration of the consumption and dispossession of companion animals. Journal of Social and Ecological Boundaries, 2(2), 34-55.

Greenebaum, J. B. (2010). Training dogs and training humans: Symbolic interaction and dog training. Anthrozoös, 23(2), 129-141. doi:10.2752/175303710X12682332909936

Groom, V., \& Nass, C (2007). Can robots be teammates? Benchmarks in human-robot teams. Interaction Studies, 8 (3), 483-500. doi:10.1075/is.8.3.10gro

Hancock, P. A. (1997). The sheepdog and the Japanese garden. In Essays on the future of humanmachine systems. Eden Prairie, MN: Banta.

Hancock, P.A. (2009). Mind, machine and morality Chapter 5. (The sheepdog and the Japanese garden.) Chichester, Engla: Ashgate. 
Hancock, P. A. (2015). Autobiomimesis. In Plenary address given at the Annual Meeting on Automotive User Interfaces. Seattle, WA.

Hancock, P. A., Billings, D. R., \& Schaefer, K. E. (2011a). Can you trust your robot? Ergonomics in Design, 19, 24-29. doi:10.1177/1064804611415045

Hancock, P. A., Billings, D. R., Schaefer, K. E., Chen, J. Y. C., de Visser, E. J., \& Parasuraman, R. (2011b). A meta-analysis of factors affecting trust in human-robot interaction. Human Factors, 53(5), 517-527. doi:10.1177/0018720811417254

Helton, W. S. (2009). Canine ergonomics: The science of working dogs. Boca Raton, FL: CRC Press.

Helton, W. S. (2010). Does perceived trainability of dog (Canis lupus familiaris) breeds reflect differences in learning or differences in physical ability? Behavioural Processes, 83 (3), 315-323.

Irvine, L. (2004). A model of animal selfhood: Expanding interactionist possibilities. Symbolic Interaction, 27(1), 3-21. doi:10.1525/si.2004.27.1.3

Jackel, L. D., Hackett, D., Krotkov, E., Perschbacher, M., Pippine, J., \& Sullivan, C. (2007). How DARPA structures its robotics programs to improve locomotion and navigation. Communications of the ACM, 50(11), 55-59. doi:10.1145/1297797.1297823

Keaveney, S. M. (2008). Equines and their human companions. Journal of Business Research, 61, 444-454. doi:10.1016/j.jbusres.2007.07.017

Kelley, T. D., \& Long, L. N. (2010). Deep Blue cannot play checkers: The need for generalized intelligence for mobile robots. Journal of Robotics, 2010(523757). doi:10.1155/2010/523757

Kemp, C. C., Edsinger, A., \& Torres-Jara, E. (2007). Challenges for robot manipulation in human environments. IEEE Robotics \& Automation Magazine, 14(1), 20-29.

Kiesler, S., \& Goetz, J. (2002). Mental models of robotic assistants. In Proceedings of the 2002 CHI Extended Abstracts on Human Factors in Computing Systems (pp. 576-577). New York, NY: ACM. doi:10.1145/506443.506491

Kiggundu, M.N. (1981). Task interdependence and the theory of job design. The Academy of Management Review, 6(3), 499-508. doi:10.5465/AMR.1981.4285795

Klinkenborg, V. (1993). If it weren't for the ox, we wouldn't be where we are. Smithsonian. 24(6), $82-90$.

Knapp, M. \& Hall, J. (2010). Nonverbal communication in human interaction. Boston, MA: Wadsworth, Cengage Learning.

Kollar, T., Tellex, S., Roy, D., \& Roy, N. (2010). Toward understanding natural language directions. In Proceedings of the $5^{\text {th }}$ Annual International Conference on Human-Robot Interaction (HRI), 259-266. Osaka, Japan: IEEE. doi:10.1109.HRI.2010.5453186

Kuhl, G. (2008). Human-sled dog relations: What can we learn from the stories and experiences of mushers? (Master's Thesis). Lakehead University, Thunder Bay, Ontario, Canada.

Kuhl, G. (2011). Human-sled dog relations: What can we learn from the stories and experiences of mushers? Society and Animals, 19(1), 22-37. doi:10.1163/156853011X545510

Lackey, S., Barber, D., Reinerman, L., Badler, N. I., \& Hudson, I. (2011). Defining nextgeneration multi-modal communication in human robot interaction. In Proceedings of the Human Factors and Ergonomics Society Annual Meeting, 55(1), 461-464. doi: $10.1177 / 1071181311551095$ 
Phillips et al., Human-Animal Teams as an Analog

Lee, J. D. \& See, K. A. (2004). Trust in automation: Designing for appropriate reliance. Human Factors, 46(1), 50-80.doi:10.1518/hfes.46.1.50_30392

Lee, S. \& Kiesler, S. (2005).Human mental models of humanoid robots. In Proceedings of the 2005 International Conference on Robotics and Automation (ICRA) (pp. 2767-2772). IEEE. doi:10.1109/ROBOT.2005.1570532

Lee, S., Kiesler, S., Lau, I., \& Chiu, C. (2005). Human mental models of humanoid robots. In Proceedings of the 2005 International Conference on Robotics and Automation (ICRA), 2767-2772. IEEE. doi:10.1109/ROBOT.2005.1570532

Long, L. N., \& Kelley, T. D. (2010). Review of consciousness and the possibility of conscious robots. Journal of Aerospace Computing, Information, and Communication, 7, 68-84. doi:10.2514/1.46188

Marble, J. L., Bruemmer, D. J., Few, D. A., \& Dudenhoeffer, D. D. (2004). Evaluation of supervisory vs. peer-peer interaction with human-robot teams. In Proceedings of the $37^{\text {th }}$ Annual International Conference on System Sciences. IEEE. doi:10.1109/HICSS.2004.1265326

McAllister, D. J. (1995). Affect- and cognition-based trust as foundations for interpersonal cooperation in organizations. The Academy of Management Journal, 38(1), 24-59. doi: $10.2307 / 256727$

Meredith, F. (n.d.). The riding tree: Communication through hands. Retrieved from http://www.meredithmanor.com/features/articles/faith/commaids.asp

Merritt, S. M., \& Ilgen, D. R. (2008). Not all trust is created equal: Dispositional and historybased trust in human-automation interactions. Human Factors, 50(2), 194-210. doi:10.1518/001872008X288574

Meyer, D. E., \& Kieras, D. E. (1997). A computational theory of executive cognitive processes and multiple-task performance: Part 1 Basic mechanisms. Psychological Review, 104(1), 3-65.

Mills, J. L. (2002). The mule. Retrieved from http://www.ecu.edu/english/tcr/20-4/mule.htm

Monette, F., Corriveau, A., \& Dubois, V. (2007). U.S. Patent No. 7,286,888. Washington, DC: U.S. Patent and Trademark Office.

Morrow, P. B., \& Fiore, S. M. (2012). Supporting human-robot teams in social dynamicism: An overview of the metaphoric inference framework. In Proceedings of the Human Factors and Ergonomics Society Annual Meeting, 56(1), 1718-1722. doi:10.1177/1071181312561344

Mortensen, M., \& Neeley, T. B. (2012). Reflected knowledge and trust in global collaboration. Management Science, 58(12), 2207-2224.

Nesbitt, B. \& Nesbitt, G. (2004). Oxen overview. Retrieved from http://www.prairieoxdrovers.com/pastpresent.html

Newell, A. (1990). Soar: A cognitive architecture in perspective. Cambridge, MA: Harvard University Press.

Newman, L. H. (2014, September). Cheetah robot is now wireless and gallivanting on MIT's campus. Slate. Retrieved from http://www.slate.com/blogs/future_tense/2014/09/15/ mit_s_cheetah_robot_is_wireless_went_outside_for_the_first_time.html

Nguyen-Huu, P. N., Titus, J., Tilbury, D., \& Ulsoy, A. G. (2009). Reliability and failure in unmanned ground vehicle (UGV) (Rep. No. GRRC Tech. Rep. 2009-01). Ann Arbor, MI: Ground Robotics Research Center, University of Michigan.

Norman, D. A. (1983). Some observations on mental models. In D. Gentner \& A. L. Stevens (Eds.), Mental Models (7-14). New York, NY: Lawrence Erlbaum Associates, Inc. 
Phillips et al., Human-Animal Teams as an Analog

Oma, K. A. (2010). Between trust and domination: Social contracts between humans and animals. World Archaeology, 42(2), 175-187. doi:10.1080/00438241003672724

Ososky, S., Philips, E., Schuster, D., \& Jentsch, F. (2013). A picture is worth a thousand mental models evaluating human understanding of robot teammates. In Proceedings of the Human Factors and Ergonomics Society Annual Meeting, 57(1), 1298-1302. doi:10.1177/1541931213571287

Ososky, S., Schuster, D., Phillips, E., \& Jentsch, F. G. (2013). Building appropriate trust in humanrobot teams. In Proceedings of the AAAI Spring Symposium: Trust and Autonomous Systems (pp. 60-65). http://www.aaai.org/ocs/index.php/SSS/SSS13/paper/viewFile/5784/6008

“Oxen Team Practice” (2010). AMomentWithRachel. [Video file]. Retrieved from http://www.youtube.com/watch?v=T_GKkumzZgE

Parasuraman, R., \& Riley, V. (1997). Humans and automation: Use, misuse, disuse, abuse. Human Factors, 39(2), 230-253. doi:10.1518/001872097778543886

Park, E., Jenkins, Q., \& Jiang, X. (2008). Measuring trust of human operators in new generation rescue robots. In Proceedings of the $7^{\text {th }}$ Annual JFPS International Symposium on Fluid Power (pp. 489-492). Toyama, Japan: JFPS. doi:10.5739/isfp.2008.489

Pepe, A. A., Ellis, L. U., Sims, V. K., \& Chin, M. G. (2008). Go, dog, go: Maze training AIBO vs. a live dog, an exploratory study. Anthrozoös, 21(1), 71-83. doi:10.2752/089279308X274074

Phillips, E., Ososky, S., \& Jentsch, F. (2014). An investigation of human decision-making in a human-robot team task. In Proceedings of the Human Factors and Ergonomics Society Annual Meeting, 58(1), 315-319. doi:10.1177/1541931214581065

Phillips, E., Ososky, S., Swigert, B., Grove, J., \& Jentsch, F. (2010). Human-animal teams as an analog for future human-robot teams. Contract No. W911NF-10-2-0016. Orlando, FL: University of Central Florida

Phillips, E., Ososky, S., Swigert, B., \& Jentsch, F. (2012). Human-animal teams as an analog for future human-robot teams. In Proceedings of the Human Factors and Ergonomics Society Annual Meeting, 56(1), 1553-1557. doi:10.1177/1071181312561309

Phillips, E. Rivera, J., \& Jentsch, F. (2013). Developing a tactical language for future robotic teammates. In Proceedings of the Human Factors and Ergonomics Society Annual Meeting, 57(1), 1283-1287. doi:10.1177/1541931213571284

Raibert, M., Blankespoor, K., Nelson, G., \& Playter, R. (2008). BigDog, the rough-terrain quadruped robot. In Proceedings of the $17^{\text {th }}$ World Congress, 17(1), 10822-10825. Korea.

Reynolds, C. W. (1987). Flocks, herds, and schools: A distributed behavioral model. In Proceedings of the $14^{\text {th }}$ Annual Conference on Computer Graphics and Interactive Techniques (SIGGRAPH) (pp. 25-34). New York, NY: ACM. doi:10.1145/37401.37406

Robinson, I. H. (1999). The human-horse relationship: How much do we know? Equine Veterinary Journal, 28, 42-45. doi:10.1111/j.2042-3306.1999.tb05155.x

Rouse, W. B., \& Morris, N. M. (1986). On looking into the black box: Prospects and limits in the search for mental models. Psychological Bulletin, 100(3), 349-363. doi:10.1037/0033-2909.100.3.349

Russell, C. (2008, November 20). \#3 Gee and Haw [Online forum comment]. Retrieved from http://www.draftanimalpower.com/showthread.php?771-Gee-and-Haw

Saavedra, R., Earley, C. P., \& Van Dyne, L. (1993). Complex interdependence in task-performing groups. Journal of Applied Psychology, 78(1), 61-72. doi:10.1037/0021-9010.78.1.61

Sanders, C. R. (1999). Understanding dogs: Living and working with canine companions. Philadelphia, PA: Temple University Press. 
Phillips et al., Human-Animal Teams as an Analog

Sanders, C. R. (2006). "The dog you deserve": Ambivalence in the K-9 officer/patrol dog relationship. Journal of Contemporary Ethnography, 35(2), 148-172. doi:10.1177/0891241605283456

Schaefer, K. E. (2013). The perception and measurement of human-robot trust (Doctoral Dissertation). University of Central Florida, Orlando, FL.

Schaefer, K. E, Adams, J. K., Cook, J. G., Bardwell-Owens, A., \& Hancock, P. A. (2015). The future of robotic design: Trends from the history of media representations. Ergonomics in Design, 23(1), 13-19. doi:10.1177/1064804614562214

Schaefer, K. E., Cook, J. G., Adams, J. K., Bell, J., Sanders, T. L., \& Hancock, P. A. (2012a). Augmented emotion and its remote embodiment: The importance of design from fiction to reality. In Proceedings of the Human Factors and Ergonomics Society Annual Meeting, 56(1), 1817-1821. doi:10.177/1071181312561366

Schaefer, K. E., Sanders, T. L., Yordon, R. E., Billings, D. R., \& Hancock, P. A. (2012b). Classification of robot form: Predicting perceived trustworthiness. In Proceedings of the Human Factors and Ergonomics Society Annual Meeting, 56(1), 1548-1552. doi:10.1177/1071181312561308

Sheppard, B. H., \& Sherman, D. M. (1998). The grammars of trust: A model and general implications (Special topic forum on trust in and between organizations). Academy of Management Review, 23(3), 422-437. doi:10.5465/AMR.1998.926619

Sheridan, T. B. (1975). Considerations in modeling the human supervisory controller. In Proceedings of the $6^{\text {th }}$ IFAC World Congress, Boston, MA: International Federation of Automatic Control.

Sheridan, T. B., \& Hennessy, R. T. (1984). Research and modeling of supervisory control behavior: Report of a workshop. Washington, D.C.: National Academy Press.

Shick, A. (2013). Romibo robot project: An open-source effort to develop a low-cost sensory adaptable robot for special needs therapy and education. In Proceedings of the ACM SIGGRAPH Studio Talks (p. 16). Anaheim, CA: ACM.

Simpson, B. S. (1997). Canine communication. The Veterinary Clinics of North America: Small Practice, 27(3), 445-464. Abstract retrieved from http://www.ncbi.nlm.nih.gov/pubmed/9170629

Sims, V. K., Chin, M. G., Sushil, D. J., Barber, D. J., Ballion, T., Clark, B. R., . . Finkelstein, N. (2005). Anthropomorphism of robotic forms: A response to affordances? In Proceedings of the Human Factors and Ergonomics Society Annual Meeting, 49(3), 602-605. doi:10.1177/154193120504900383

Sowa, J. F. (2006). Categorization in cognitive computer science. Amsterdam: Elsevier.

Staats, S., Wallace, H., \& Anderson, T. (2008). Reasons for companion animal guardianship (pet ownership) from two populations. Society and Animals, 16(3), 279-291. doi:10.1163/156853008X323411

Subbaraman, N. (2013). My robot friend: People find real comfort in artificial companions. Retrieved from: http://www.nbcnews.com/tech/innovation/my-robot-friend-people-findreal-comfort-artificial-companionship-f6C10146787

Tanaka, F., \& Matsuzoe, S. (2012). Children teach a care-receiving robot to promote their learning: Filed experiments in a classroom for vocabulary learning. Journal of HumanRobot Interaction, 1(1), 78-95. doi:10.5898/JHRI.1.1.Tanaka

The Hunting Dog (2008). Communicate with dog training hand signals. Retrieved from http://www.the-hunting-dog.com/dog-training-hand-signals.html

The Robinson Ranch. (2003). What can a donkey do? Retrieved from http://www.donkeys.com/info2.htm

Thompson, J. D. (1967). Organizations in action. New York: McGraw-Hill. 
Torrey, C., Fussell, S. R.., \& Kiesler, S. (2013). How a robot should give advice. In Proceedings of the 8th International Conference on Human-Robot Interaction (HRI) (pp.275-282). NJ: IEEE.

Upham Ellis, L., Sims, V. K., Chin, M. G., Pepe, A. A., Owens, C. W., Dolezal, M. J., Shumaker, R., \& Finkelstein, N. (2005). Those a-maze-ing robots: Attributions of ability are based on form, not behavior. In Proceedings of the Human Factors and Ergonomics Society Annual Meeting, 49(3), 598-601. doi:10.1177/154193120504900382

Vaughan, R. T., Støy, K., Sukhatme, G., \& Matarić, M. J. (2002). LOST: Localization-space trails for robot teams. Robotics and Automation, 18(5), 796-812. doi:10.1109/TRA.2002.803459

Victor, B., \& Blackburn, R.S. (1987).Interdependence: An alternative conceptualization. Academy of Management Review, 12 (3), 486-498.

Volosyak, I., Ivlev, O., \& Graser, A. (2005). Rehabilitation robot FRIEND II-The general concept and current implementation. In Proceedings of the $9^{\text {th }}$ Annual International Conference on Rehabilitation Robotics (pp. 540-544). IEEE. doi:10.1109/ICORR.2005.1501160

Walsh, F. (2009). Human-animal bonds 1: The relational significance of companion animals. Family Process, 48 (4), 462-480.

Watts, K., \& Everly, J. S. (2009). Helping children with disabilities through animal-assisted therapy. The Exceptional Parent, 39(5), 1-34.

Werner, D. (2013, June). Drone swarm: Networks of small UAVs offer big capabilities. Defense News. Retrieved from http://www.defensenews.com/article/20130612/C4ISR/306120029/DroneSwarm-Networks-Small-UAVs-Offer-Big-Capabilities

Wesley, M. C., Minatrea, N. B., \& Watson, J. C. (2009). Animal-assisted therapy in the treatment of substance dependence. Anthrozoös, 22 (2), 137-148. doi:10.2752/175303709X434167

Wilson, C. C. (1994). A conceptual framework for human-animal interaction research: The challenge revisited. Anthrozoös, 7(1), 4-24. doi:10.2752/089279394787002032

Yeon, S. C. (2007). The vocal communication of canines. Journal of Applied Veterinary Behavior: Clinical Applications and Research, 2(4), 141-144. doi:10.1016/j.jveb.2007.07.006

Yorke, J., Adams, C., \& Coady, N. (2008). Therapeutic value of equine-human bonding in recovery from trauma. Anthrozoos, 21(1), 17-30. doi:10.2752/089279308X274038

Yoshitaka, F., Masayoshi, K., Taro, S., Masaru, S., \& Tsuyoshi, N. (2012). Subjective evaluation of use of Babyloid for doll therapy. In Proceedings of the IEEE International Conference on Fuzzy Systems (FUZZ-IEEE). Brisbane, Australia: IEEE. doi:10.1109/FUZZ-IEEE.2012.6251247

Zapf, S. A., \& Rough, R. B. (2002). The development of an instrument to match individuals with disabilities and service animals. Disability and Rehabilitation, 24(1-3), 47-58. doi:10.1080/09638280110066316

Zasloff, R. L. (1996). Measuring attachment to companion animals: A dog is not a cat is not a bird. Applied Animal Behaviour Science, 47, 43-48. doi:10.1016/0168-1591(95)01009-2

Elizabeth Phillips, Institute for Simulation and Training, University of Central Florida, Orlando, Florida, USA. ephillip@ist.ucf.edu; Kristin E. Schaefer, U.S. Army Research Laboratory, Aberdeen Proving Ground, MD, USA. kristin.e.schaefer2.ctr@mail.mil; Deborah R. Billings, Agilis Consulting Group, Cave Creek, AZ, USA. dbillings@agilisconsulting.com; Florian Jentsch, Institute for Simulation and Training, University of Central Florida, Orlando, Florida, USA. fjetsch@ist.ucf.edu; Peter A. Hancock, University of Central Florida, Orlando, Florida, USA. peter.hancock@ucf.edu. 